\title{
Drei auffällige Passionsblumen im Palmengarten
}

\author{
Sonja Luetgehetmann
}

\begin{abstract}
Passion flowers are attractive ornamental plants because of their unusual flower shape. Most of them are not hardy, only a few can be planted outside. Passiflora caerulea and P. 'Pura Vida' are well-known ornamental plants. Passiflora helleri is cultivated because of its exciting leaves. Glands on the leaves imitate eggs of butterflies (Heliconius). The fruits of passion flowers, from which the maracuja juice is extracted, have economic significance.
\end{abstract}

\section{Zusammenfassung}

Passionsblumen sind wegen ihrer außergewöhnlichen Blütenform attraktive Zierpflanzen. Die meisten sind bei uns nicht winterhart, nur wenige lassen sich im Freien ausgepflanzt kultivieren. Passiflora caerulea und P. 'Pura Vida' sind bekannte Zierpflanzen. Passiflora helleri wird wegen ihrer spannenden Blätter kultiviert. Drüsen auf den Blättern sind Eiattrappen. Sie halten Weibchen der Passionsblumenfalter davon ab, Eier auf den Blättern abzulegen. Die Früchte von Passionsblumen, aus denen der Maracujasaft gewonnen wird, haben ökonomische Bedeutung.

\section{Attraktive Kletterpflanzen}

Passionsblumen (Passiflora) erfreuen sich aufgrund ihrer attraktiven Blüten großer Beliebtheit als Zimmerpflanzen. Die meisten Arten sind Kletterpflanzen. Gelegentlich gibt es blühende und dann meist zu einem Bogen gewundene Pflanzen sogar in den Blumenabteilungen von Discountern zu kaufen. Die Vielfalt der Passionsblumen ist groß. Die Gattung umfasst gut 500 Arten und ist dabei die artenreichste Gattung innerhalb der Passionsblumengewächse (Passifloraceae). Die meisten Arten kommen in den Tropen der Neuen Welt vor, wobei es auch ein paar wenige Vertreter in

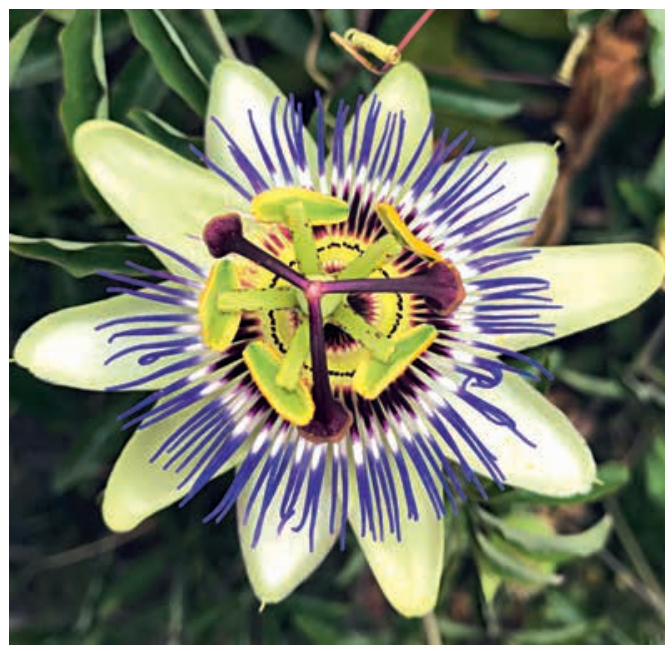

Abb. 1: Passiflora caerulea am Eingang zum Tropicarium. (Foto: S. Luetgehetmann) der Paläotropis gibt. Aufgrund ihrer tropischen bis subtropischen Verbreitung sind Passionsblumen wärmeliebend und mit wenigen Ausnahmen wie z. B. Passiflora caerulea bei uns nicht für die Freilandkultur geeignet. Der Palmengarten beherbergt Passionsblumen in den Schauhäusern sowie im Freien.

\section{Die Blaue Passionsblume für draußen}

Die winterharte Blaue Passionsblume (Passiflora caerulea) gedeiht an der Lärmschutzwand am Garten der Bildungseinrichtung „Kinder im Garten“. Einen besonderen Blickfang bildet sie aber auch am Eingang zum Mangroven- und KüstenwälderHaus des Tropicariums. Die meisten Passionsblumen sind Kletterpflanzen wie auch $P$. caerulea. Sie bilden nur an neuen Trieben ihre Blüten aus. Passiflora caerulea entwickelt den ganzen Sommer bis in den Frühherbst hinein 6-10 cm große, prächtige Blüten, die aufgrund ihrer faszinierenden, strahlend blau-weißen Färbung sofort ins Auge fallen. Auch ihr Blütenaufbau ist ungewöhnlich und regte früher christliche Einwanderer in Südamerika zu Vergleichen mit der Passion Christi an, worauf sich deutscher sowie wissenschaftlicher Name beziehen. So sollen die drei Narben die drei Nägel am Kreuz, der rote Kranz der Nebenkrone die Dornenkrone, die fünf Staubblätter die Wundmale, die spitzen Blätter die römischen Lanzen und die Ranken die Geißel symbolisieren. Abgesehen von diesem Grundgerüst können sich die über 


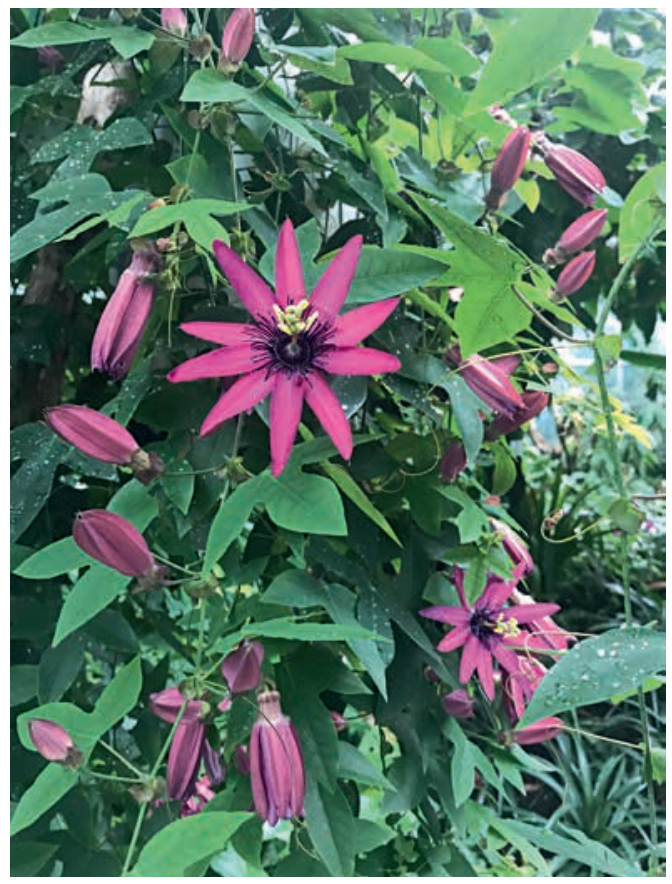

Abb. 2: Passiflora 'Pura Vida' rankt üppig im BromelienHaus. (Foto: S. Luetgehetmann)

500, hauptsächlich neotropischen Passiflora-Arten in ihrer Gestalt jedoch stark unterscheiden.

\section{Passionsblumen im Gewächshaus}

Eine ähnliche Blütenform wie $P$. caerulea zeigt $P$. 'Pura Vida', eine Hybride zwischen $P$. 'Amethyst' und $P$. racemosa. Sie mag keine Temperaturen unter $8^{\circ} \mathrm{C}$, weshalb sie für die Gewächshauskultur oder den Wintergarten geeignet ist. Sie gedeiht bei uns im Bromelien-Haus des Tropicariums und bildet über den Sommer hinweg unzählige, etwa $10 \mathrm{~cm}$ breite Blüten mit einer besonders auffälligen, attraktiven rotvioletten Farbe. Sie wird als robuste Zierpflanze im Handel angeboten und in wärmeren Gebieten zur Fassadenbegrünung empfohlen.

Außer den Blüten sind bei manchen Arten aber auch die Blätter beachtenswert. Ebenfalls im Bromelien-Haus rankt die aus Mexiko stammende Hellers Passionsblume (Passiflora helleri). In Kultur blüht sie sehr selten. Im Allgemeinen haben Passionsblumen giftige Blätter. Dies nutzen die farbenprächtigen Passionsblumenfalter (Heliconius) aus. Sie legen ihre Eier auf die Blätter von

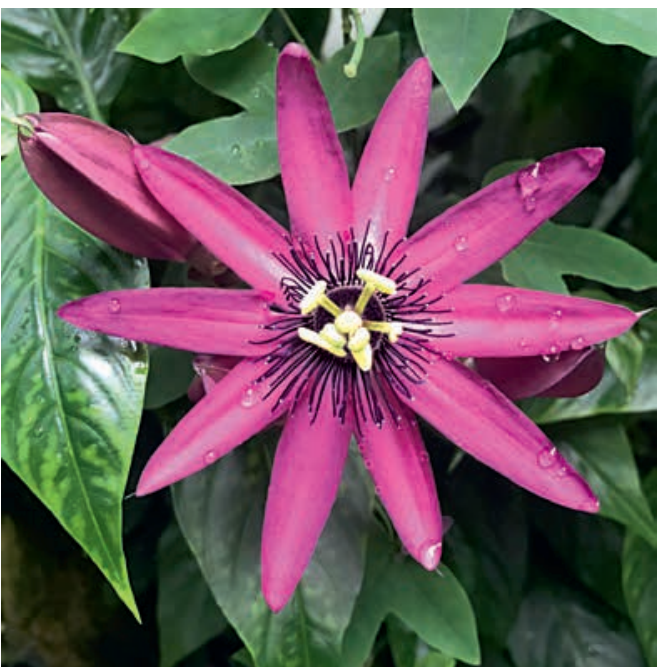

Abb. 3: Einzelblüte von $P$. 'Pura Vida'.

(Foto: S. Luetgehetmann)

Passionsblumen. Die Raupen sind gegenüber dem Gift resistent und nehmen mit dem Fressen der Blätter sogar das Gift in sich auf, wodurch sie und später auch die Falter für Fressfeinde uninteressant werden. Die Raupen der Passionsblumenfalter sind Kannibalen, denn bevor die jungen Raupen mit dem Fressen der Blätter beginnen, fressen sie alle übrigen Eier ihrer Artgnossen, die sich auf „ihrem“ Blatt befinden, um somit Nahrungskonkurrenten auszuschalten. Deshalb vermeiden es die Heliconius-Weibchen nach Möglichkeit, Eier auf Blättern abzulegen, die schon mit Eiern belegt sind. Auf den Blättern von P. helleri befinden sich zwei Reihen heller Punkte. Es handelt sich um Eiattrappen, die die Heliconius-Falter davon abhalten

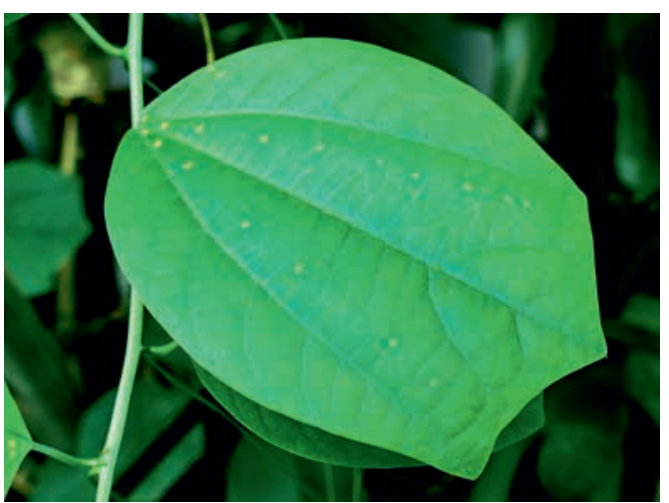

Abb. 4: Blatt von P. helleri mit Eiattrappen. (Foto: H. STEINECKE) 


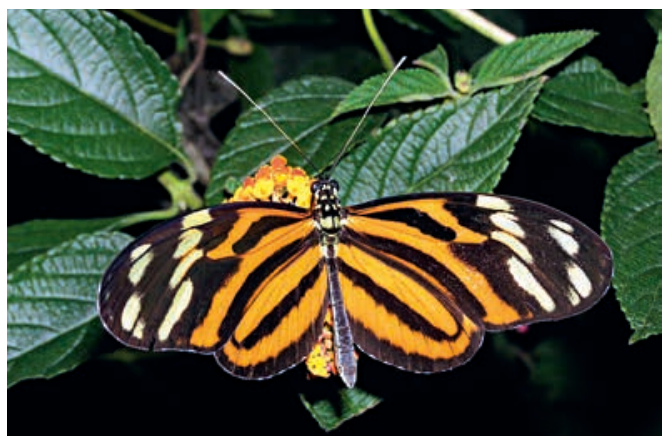

Abb. 5: Eine der vielen Passionsblumenfalter-Arten (Heliconius hecale). Passionsblumenfalter sind beliebte Arten in Schmetterlingshäusern und werden in Zukunft auch im Blüten- und Schmetterlingshaus des Palmengartens zu sehen sein. (Foto: H. STEINECKe)

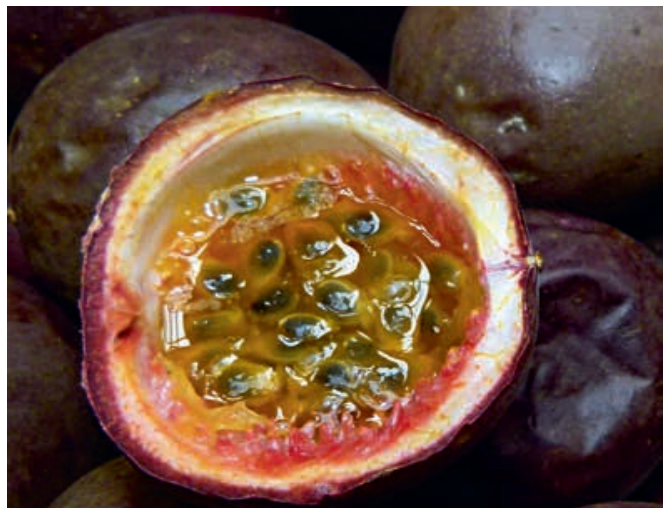

Abb. 6: Geöffnete Passiflora-Frucht. Gut zu erkennen sind die zahlreichen Samen, die von einem saftigen Arillus umgeben sind. (Foto: H. Steinecke)

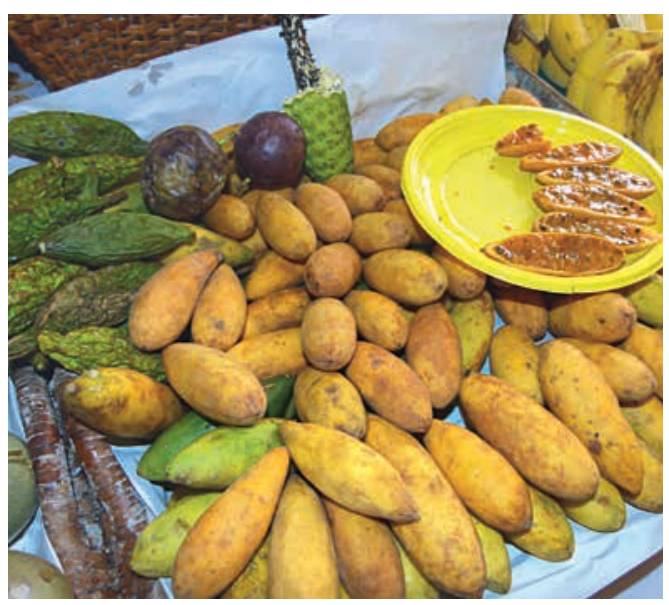

Abb. 7: Bananen-Maracujas, die Früchte von P. tarminiana, in der Markthalle in Funchal. (Foto: H. Steinecke) sollen, hier ihre Eier abzulegen. Die Punkte sind Nektardrüsen. Der aus ihnen abgeschiedene Nektar lockt Ameisen an. Um nicht ihre Nektarquelle zu verlieren, bekämpfen die Ameisen gegebenenfalls die das Blatt fressenden Raupen.

\section{Lecker und heilsam}

Die Früchte der Passionsblumen sind sogenannte Lederbeeren. Die Fruchtwand (Perikarp) trocknet bei den reifen Beeren aus und wird lederartig. In einer vom Perikarp gebildeten Zentralhöhle befinden sich zahlreiche Samen, welche jeweils von einem verschleimenden Arillus (Samenmantel) umschlossen sind. Dieser Arillus hat ein saftreiches Gewebe, das essbar ist und süß-säuerlich schmeckt. Die bei uns bekannte Maracuja ist die Frucht der aus Südamerika stammenden Passiflora edulis. Ihr Name stammt aus dem Portugiesischen, wobei „mara“ für Speise und „cuja“ für Gefäß steht.

Inzwischen werden Passionsblumen weltweit in den Tropen und Subtropen angebaut. Nach Europa kamen sie bereits im 17. Jahrhundert, vor allem als Zierpflanzen wegen ihrer auffälligen Blüten. Passionsblumenfrüchte gehören auf unseren Obsttheken mittlerweile zum Standardsortiment. Wer schon einmal auf Madeira war und dort die berühmte Markthalle in Funchal besucht hat, hat dort vermutlich die große Vielfalt verschiedenster Maracuja-Früchte kennengelernt. Auf Madeira besonders beliebt ist die Bananen-Maracuja. Die Früchte stammen von $P$. tarminiana. Sie ist nur aus Kultur bekannt und in vielen warmen Ländern, auch auf Madeira, ein invasiver Neophyt.

Inzwischen werden Extrakte aus den krautigen Teilen der Pflanze auch als Arzneidroge gegen nervöse Unruhe eingesetzt. Im Jahr 2011 wurde P. incarnata zur Arzneipflanze des Jahres gekürt. Maracuja-Saft findet sich in vielen Getränken. Weiterhin bekannt ist die Süße Grenadille, die Frucht von P. ligularis.

\section{Anschrift der Autorin}

Sonja Luetgehetmann, Neustadt 2, 37073 Göttingen, E-Mail: sonjaluetgehetmann@gmx.de 